\title{
An improved method for calculating critical temperatures and critical pressures in natural gas mixtures with up to $n C_{11}$ hydrocarbons
}

\author{
Marvin Ricaurte*, José M. Fernández, and Alfredo Viloria \\ School of Chemical Sciences and Engineering, Yachay Tech University, San Miguel de Urcuquí 100650, Ecuador
}

Received: 24 January 2019 / Accepted: 15 April 2019

\begin{abstract}
This study suggests an improvement to the empirical model proposed by Peng (1986, Can. J. Chem. Eng. 64, 827-830) to calculate critical temperatures and critical pressures in natural gas mixtures. It aims to extend its application to natural gas mixtures containing hydrocarbons compounds up to undecane $\left(n \mathrm{C}_{11}\right)$. This work focuses on establishing new matrices of coefficients $A_{i j}$ by obtaining new binary interactions between heavy compounds and the rest of compounds present in natural gas mixtures. The analysis considered more than 300 natural gas mixtures. Different comparisons were made between calculated critical properties, and referenced critical properties. Mean absolute errors $<1.00 \%$ for the critical temperatures, and $<2.70 \%$ for critical pressures were obtained. These low average deviations demonstrate the accuracy of this study, and could be considered as an easy-to-use engineering tool for estimating critical properties in natural gas mixtures, applicable to lean gas, rich gas, gas condensate, and Natural Gas Liquids (NGL).
\end{abstract}

\section{Introduction}

Natural gas is a mixture of hydrocarbon compounds, which are in a gaseous state under most ambient conditions. This mixture is mainly composed of paraffinic hydrocarbons molecules, from methane $\left(\mathrm{C}_{1}\right)$ to undecane $\left(n \mathrm{C}_{11}\right)$, and some impurities, such as carbon dioxide $\left(\mathrm{CO}_{2}\right)$, hydrogen sulfide $\left(\mathrm{H}_{2} \mathrm{~S}\right)$, nitrogen $\left(\mathrm{N}_{2}\right)$, and water vapor $\left(\mathrm{H}_{2} \mathrm{O}\right)(\mathrm{Gas}$ Processors Suppliers Association, 1998). Given the industrial importance of natural gas as an energy vector in the 21st century, it is necessary to count with thermodynamic-based models to calculate or estimate physical and chemical properties of interest in the oil and gas industry (Mazyan et al., 2016; Nasrifar and Rahmanian, 2018). Among their industrial applications are: incrementing oil recovery factors from reservoirs (Sayed and Al-Muntasheri, 2016), production and operational analyses for transport of natural gas in onshore and offshore environments (Campos et al., 2017), design of surface facilities for processing natural gas (Yang et al., 2018), and underground natural gas storage studies (Demirel et al., 2017).

Traditionally, composition of natural gas mixtures is reported up to heptane $\left(n \mathrm{C}_{7}\right)$, even though in the natural gas industry, some of these mixtures (rich gas) could have a significant content of paraffins larger than $n \mathrm{C}_{7}$. New

\footnotetext{
* Corresponding author: mricaurte@yachaytech.edu.ec
}

developments on chromatographic techniques to characterize natural gas mixtures, it is now common practice to determine, with a high degree of accuracy, the hydrocarbon content up to undecane $\left(n \mathrm{C}_{11}\right)$ (Faramawy et al., 2016; International Organization for Standardization, 2000).

There are rigorous and empirical methods to calculate critical properties of Vapor-Liquid Equilibrium (VLE) in multicomponent mixtures, applied to natural gas samples (Huang and Guo, 1995). Rigorous methods are based on classical thermodynamic theories, and on the concept of Helmholtz free energy minimization (Bell and Jäger, 2017), which require simultaneous resolution of non-linear equation systems. Several authors have proposed different strategies and algorithms to solve these equation systems (Heidemann and Khalil, 1980; Michelsen, 1980; Peng and Robinson, 1977). On the other hand, empirical methods are mathematical correlations used to calculate directly critical properties (Ahmed, 2016). Peng (1986) suggested an empirical method to calculate critical temperature $\left(T_{\mathrm{c}}\right)$ and critical pressure $\left(P_{\mathrm{c}}\right)$ in natural gas mixtures, which was based on the concept of excess function (Eq. (1)):

$$
\phi-\sum_{i} x_{i} \phi_{i}=-C \sum_{i} x_{i} \ln \left(\sum_{j} x_{j} A_{i j}\right),
$$

where $\phi$ is the desired critical property $\left(T_{\mathrm{c}}\right.$ or $\left.P_{\mathrm{c}}\right), x_{i}$ and $x_{j}$ molar composition of the studied mixture, $\phi_{i}$ critical 
Table 1. Number of natural gas samples considered in this study.

\begin{tabular}{|c|c|c|}
\hline \multirow[t]{2}{*}{ Natural gas samples } & \multicolumn{2}{|l|}{ Sections } \\
\hline & Excess function optimization & Validation \\
\hline Lean gas & 65 & 41 \\
\hline Rich gas & 134 & 67 \\
\hline Total & 199 & 108 \\
\hline References & $\begin{array}{l}\text { Atilhan et al. (2010), Ávila et al. }(2002,2006) \text {, } \\
\text { Farzaneh-Gord et al. (2015), Guerrero-Zárate et al. } \\
\text { (2017), Justo-García et al. (2008), Kunz and } \\
\text { Wagner (2012), Nasir et al. (2015), Nasrifar et al. (2005) }\end{array}$ & $\begin{array}{l}\text { Jaeschke and Humpherys (1991), Jiang } \\
\text { and Prausnitz (2000), Louli et al. (2012) }\end{array}$ \\
\hline
\end{tabular}

properties of individual components, $C$ an arbitrary constant, and $A_{i j}$ fitted parameter for component pair $i-j$. Despite its easy-to-use implementation, it is limited to paraffins raging from methane through $n \mathrm{C}_{7}$ (Bahadori, 2014), so its application to rich gas mixtures is not recommended (Huang and Guo, 1995).

This paper suggests an enhanced approach to the method proposed by Peng (1986). It takes into account, the effect of heavy paraffins (namely, $n \mathrm{C}_{7}, n \mathrm{C}_{8}, n \mathrm{C}_{9}$, $n \mathrm{C}_{10}$, and $\left.n \mathrm{C}_{11}\right)$ in calculating critical properties $\left(P_{\mathrm{c}}\right.$ and $T_{\mathrm{c}}$ ) in natural gas mixtures. This improved approach mainly focuses on optimizing the excess function (Eq. (1)), by proposing new matrices of coefficients $A_{i j}$, which consider the interaction between heavy paraffins and the rest of components present in natural gas. The significance of this study is that it extends the applicability of the method of Peng (1986), to calculate critical properties of natural gas mixtures containing considerable amounts of heavy hydrocarbons, i.e., rich gas, gas condensates, and Natural Gas Liquids (NGL) (Faramawy et al., 2016; Jin and Lim, 2018).

\section{Methods}

Figure 1 shows a schematic representation of the methodology developed in this study. It is divided into two sections: (i) excess function optimization, and (ii) validation of calculated critical properties. Samples used during the excess function optimization section (Data Set 1) were different from the ones used for the validation section (Data Set 2).

In both sections, the criteria to classify the natural gas is based on the content of $\mathrm{C}_{2}^{+}$(Faramawy et al., 2016). Natural gas containing $\leq 10 \mathrm{~mol} \%$ of $\mathrm{C}_{2}^{+}$is considered "lean gas", and natural gas containing $>10 \mathrm{~mol} \%$ of $\mathrm{C}_{2}^{+}$is defined as "rich gas".

(i) Excess function optimization section: critical temperatures and critical pressures were obtained from Data Set 1 using commercial chemical process simulators (e.g., SimSci Pro/II, Aspen Hysys, and PVTSim Nova), with Peng and Robinson (1976) Equation of
State (EoS), as the suitable thermodynamic model. Details on the accuracy and confidence of thermodynamic packages used by chemical process simulators can be found in a recent book by Foo et al. (2017). The arithmetic average of critical properties obtained from the simulators was taken for each sample $\left(P_{\mathrm{c}} \&\right.$ $T_{\mathrm{c}}$ Data 1$)$, and used as "critical properties reference".

(ii) The critical properties are fitted using the Peng (1986) correlation by defining new matrices coefficients $A_{i j}$, in order to obtain an enhanced excess function. This optimization analysis was performed using the MatLab Optimization Toolbox (MathWorks, 2018).

(iii) Validation section: this section was performed using a set of natural gas samples different than those used in the excess function optimization section, thus assuring that the enhanced excess function presented in this study, is not dependent of the dataset used to determine the matrices coefficient $A_{i j}$. Critical pressures and temperatures obtained from the enhanced excess function were compared against critical properties calculated from three different sources:

- Comparison A: it considers the average of the results obtained from chemical process simulators.

- Comparison B: it considers results using the original proposal of Peng (1986).

- Comparison $C$ : it takes into consideration some models available in the literature to predict vapor-liquid equilibrium properties, including critical points (Justo-García et al., 2008; Nasrifar et al., 2005; Guerrero-Zárate et al., 2017; Jiang and Prausnitz, 2000). These models use experimental critical temperatures and pressures to verify accuracy. The comparison $\mathrm{C}$ shows the applicability and robustness of the current study against available models.

\subsection{Natural gas mixtures}

Table 1 shows number of natural gas mixtures used in this study. It includes both natural gas mixtures to determine 


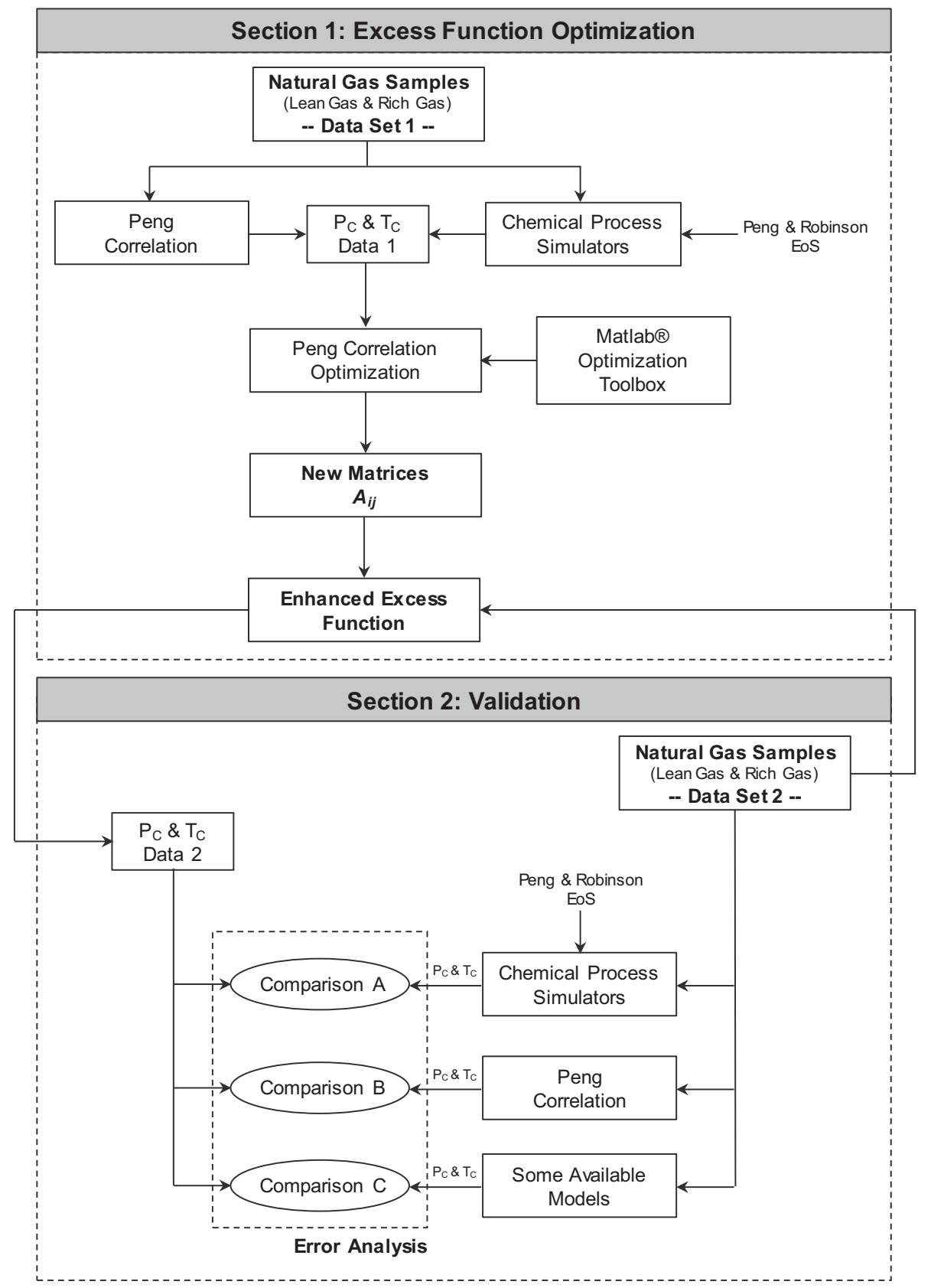

Fig. 1. Schematic representation of the methodology developed in this study.

matrices coefficients $A_{i j}$ (199 samples), and natural gas mixtures to validate critical properties calculated (108 samples).

The total number of natural gas mixtures considered was 307 , of which $65.5 \%$ were rich gas samples from associated and non-associated gas fields (Faramawy et al., 2016). To demonstrate the molar composition amplitude of the samples considered in this study, all natural gas samples were classified taking into account: (a) $\mathrm{C}_{1}$ content in lean gas and rich gas, (b) content of non-hydrocarbon compounds and (c) the content of heavy compounds (Fig. 2).

\subsection{Calculation method used to obtain matrices coefficients $A_{i j}$}

Matrices coefficients were optimized using the least-squares method of estimated errors for each critical temperature and pressure analyzed. Equation (1) governing the behavior of the critical constants is the same as that used by Peng (1986).

The new matrices of coefficients $A_{i j}$ are squares matrices of order 16. The order of a matrix corresponds to its number of compounds in natural gas mixtures: paraffinic hydrocarbons (from $\mathrm{C}_{1}$ to $n \mathrm{C}_{11}$ ), and non-hydrocarbon compounds 


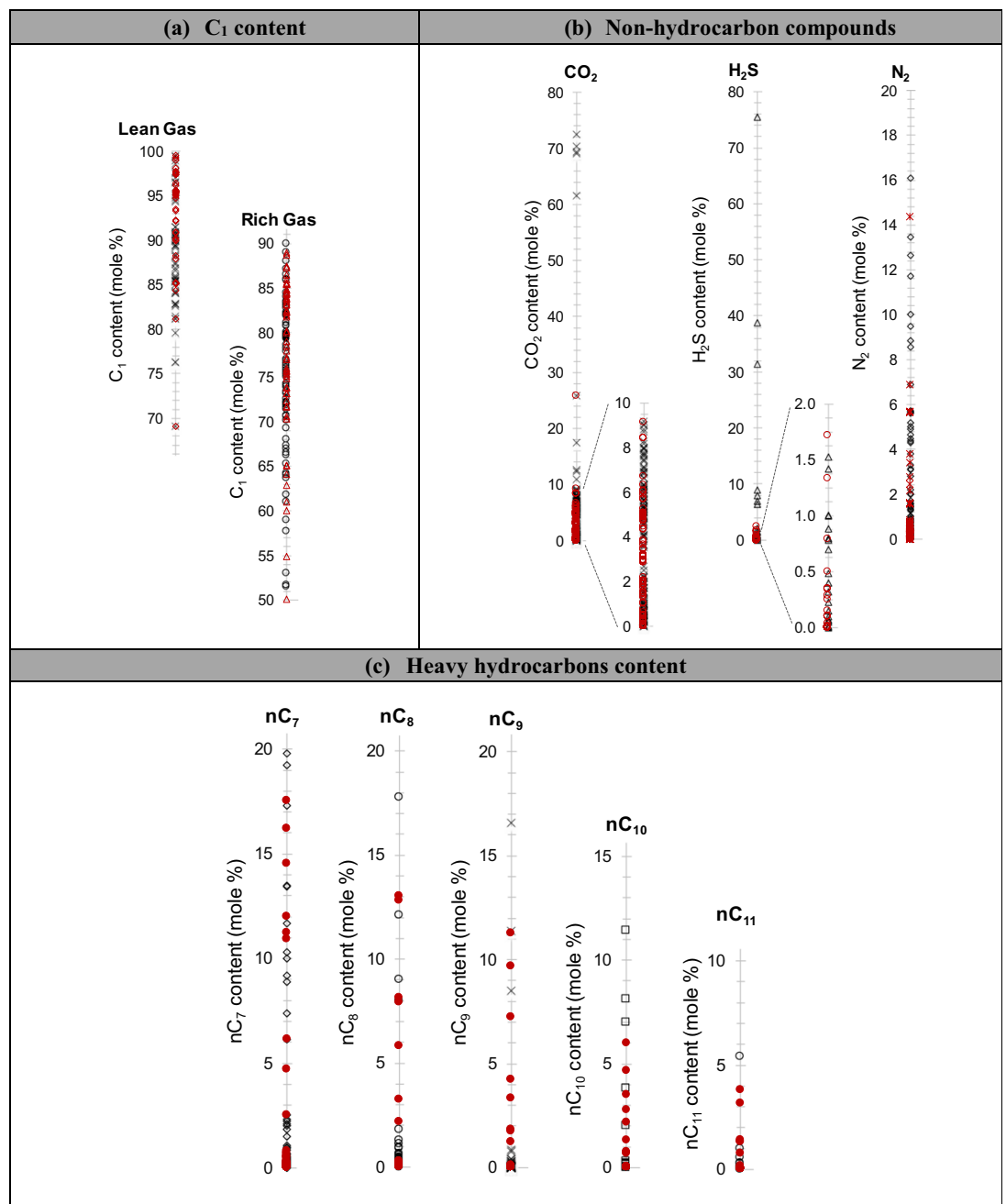

Fig. 2. Characterization of natural gas samples: a) $\mathrm{C}_{1}$ content in lean gas and rich gas, b) non-hydrocarbon compounds, and c) heavy compounds content. (Note: black symbols represent the Data Set 1 used in excess function optimization and red ones denote the Data Set 2 for validation section).

$\left(\mathrm{N}_{2}, \mathrm{CO}_{2}\right.$, and $\left.\mathrm{H}_{2} \mathrm{~S}\right)$. The form of matrix $A_{i j}$ is given by equation (2):

$$
A_{i j}=\left(\begin{array}{ccccccc}
1 & a_{12} & a_{13} & \cdot & \cdot & \cdot & a_{1 n} \\
a_{21} & 1 & a_{13} & \cdot & \cdot & \cdot & a_{2 n} \\
a_{31} & a_{32} & 1 & \cdot & \cdot & \cdot & a_{3 n} \\
\cdot & \cdot & \cdot & \cdot & & \cdot \\
\cdot & \cdot & \cdot & & \cdot & & \cdot \\
\cdot & \cdot & \cdot & & & \cdot & \cdot \\
a_{n 1} & a_{n 2} & a_{n 3} & \cdot & \cdot & \cdot & 1
\end{array}\right) .
$$

The coefficients $a_{i j}$ of matrix $A_{i j}$ can be considered as the binary relationship between the different hydrocarbon molecules in a natural gas mixture. Binary relationships between same hydrocarbon molecules are assumed to be
1 , therefore, unit values are assigned to the elements in the main diagonal of each matrix (Peng, 1986).

Matrices coefficients $A_{i j}$ were calculated using the Levenberg-Marquardt method (Marquardt, 1963), which was implemented using MatLab Optimization Toolbox. The function to be minimized (Eq. (3)) was established from the quadratic difference between the value calculated using equation (1) $\left(f\left(x_{i}\right)\right)$ and the average value obtained with simulators $\left(y_{i}\right)$ for a given number $(N)$ of natural gas mixtures:

$$
E(f)=\frac{\sum_{i}^{N}\left(f\left(x_{i}\right)-y_{i}\right)^{2}}{N} .
$$

The average absolute percentage error is determined using equation (4), and considering $y_{i}$ as the correct value:

$$
\text { Error }=\frac{\left|f\left(x_{i}\right)-y_{i}\right|}{y_{i}} \times 100 \% .
$$




\section{Results}

\subsection{Determination of coefficients matrices $A i j$ and calculation of critical properties}

Tables 2 and 3 show new matrices coefficients $A_{i j}$ established to calculate critical properties of natural gas mixtures using equation (1). The first subscript (i) corresponds to rows and the second subscript $(j)$ to columns on the new matrices. The constant $C$ was assumed as $2500 \mathrm{~K}$ for calculation of critical temperatures, and $250 \mathrm{MPa}$ for calculation of critical pressures.

Figure 3 shows results comparison between results obtained from analyzed mixtures to determine coefficients $A_{i j}$.

Figure 3, graphs (a) and (b), shows that calculated critical properties behave similarly to the reference values. These results deviate from the expected values by less than $10 \%$ in both cases. Critical temperature results presented less statistical dispersion. Critical pressure results presented greater dispersion, only four out of 199 natural gas mixtures showed results with deviations greater than $10 \%$.

Mean absolute percentage errors were $<1.00 \%$ for critical temperatures results, and $<2.70 \%$ for the critical pressure (Fig. 3c). These average errors are acceptable when compared to mean errors reported in the literature (Sloan and Koh, 2008). These small dispersion values confirm the reliability of all selected mixtures, and a high level of statistical confidence to the applied method. With respect to the type of sample, a higher dispersion of the results was found in lean gas samples.

\subsection{Validation}

Validation was performed using natural gas mixtures other than those used to calculate the coefficients $A_{i j}$ (Sect. 3.1). Using these natural gas mixtures, confirm the applicability and robustness of the proposed modification to the correlation by Peng (1986) in this study.

\subsubsection{Comparison $A$}

Figure 4 shows the comparison of results considering average errors from results obtained using simulators.

Average errors of $0.90 \%$ for the critical temperature and $2.61 \%$ for the critical pressure were obtained on all natural gas mixtures. These errors are within the same error range obtained in Section 3.1. Lean gas mixtures have the highest error dispersion and average absolute deviation error.

\subsubsection{Comparison $B$}

Comparison B (Tab. 4) is made limiting contents of $n \mathrm{C}_{7}$ in natural gas mixtures. Two types of mixtures were considered: (1) natural gas mixtures containing hydrocarbons molecules lighter than or equal to $n \mathrm{C}_{7}\left(\leq n \mathrm{C}_{7}\right)$, and (2) natural gas mixtures containing hydrocarbons molecules up to $n \mathrm{C}_{11}$.

Due to the fact that the semi-empirical model developed by Peng (1986), considers only mixtures up to $n \mathrm{C}_{7}$, for mixtures type (2) components heavier than $n \mathrm{C}_{7}$ and components (a)

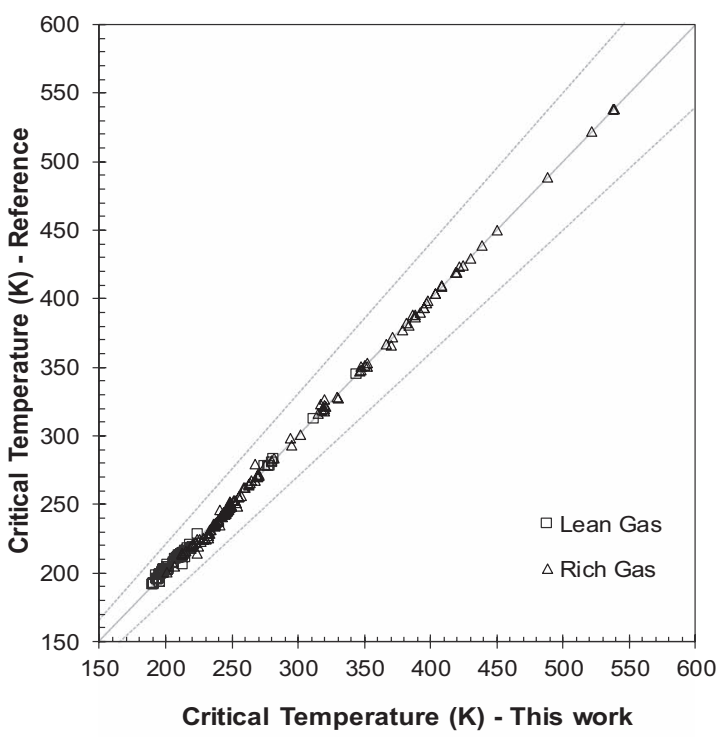

(b)

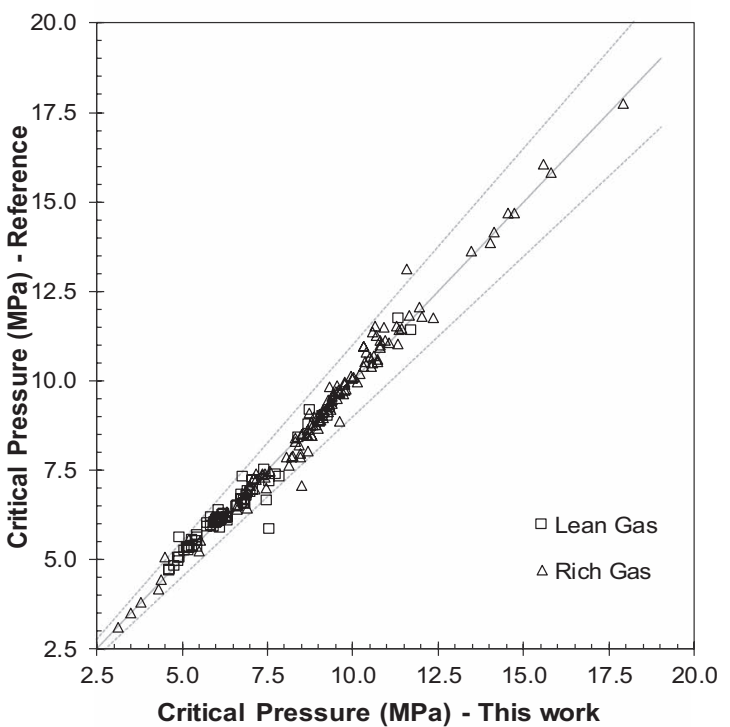

(c)

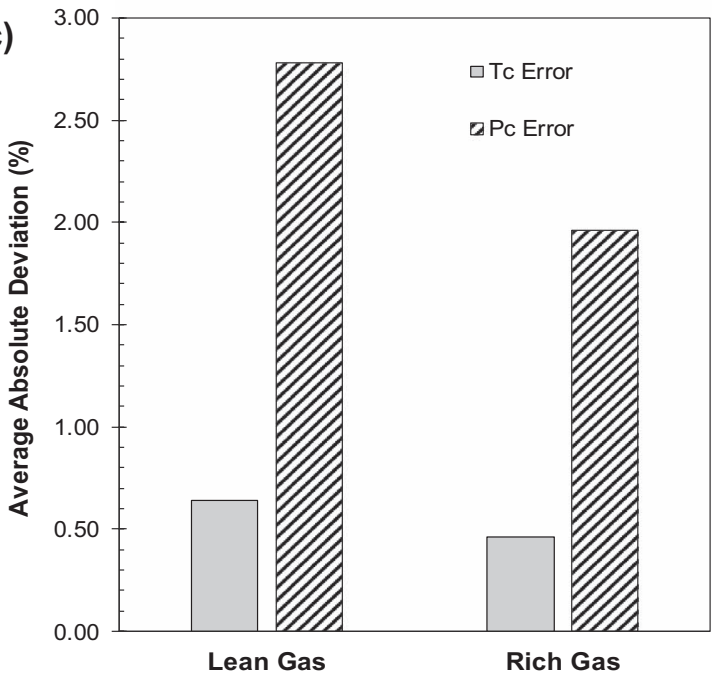

Fig. 3. Critical property calculations: a) critical temperatures, b) critical pressures, and c) Average Absolute Deviation (AAD). 
Table 2. Coefficients $\left(A_{i j}\right)$ for the calculation of critical temperatures.

\begin{tabular}{|c|c|c|c|c|c|c|c|c|c|c|c|c|c|c|c|c|}
\hline & $\mathrm{C}_{1}$ & $\mathrm{C}_{2}$ & $\mathrm{C}_{3}$ & $\mathrm{iC}_{4}$ & $n \mathrm{C}_{4}$ & $\mathrm{iC}_{5}$ & $n \mathrm{C}_{5}$ & $n \mathrm{C}_{6}$ & $n \mathrm{C}_{7}$ & $n \mathrm{C}_{8}$ & $n \mathrm{C}_{9}$ & $n \mathrm{C}_{10}$ & $n \mathrm{C}_{11}$ & $\mathrm{~N}_{2}$ & $\mathrm{CO}_{2}$ & $\mathrm{H}_{2} \mathrm{~S}$ \\
\hline $\mathrm{C}_{1}$ & 1 & 0.4306 & 0.5681 & 0.3543 & 7575 & 1.0390 & 1.0688 & 0.9008 & 0.6710 & 2.7370 & 0.8322 & 1.7854 & 1.2145 & 1.1158 & 0.4491 & 0.3818 \\
\hline $\mathrm{C}_{2}$ & 1.7151 & 1 & 1.1426 & 1.4614 & 0.9240 & 1.8367 & 1.2249 & 1.6951 & 1.3011 & -0.3532 & .9119 & 0.2496 & 0.7335 & & 1.4547 & 0.9249 \\
\hline $\mathrm{C}_{3}$ & 1.4638 & 0.8944 & 1 & 1.8228 & 0.9249 & 0.6913 & 1.1442 & 1.6184 & 1.9647 & -0.5300 & 0.7312 & 0.9636 & 0.5793 & 0.7448 & 0.7884 & 1.5769 \\
\hline $\mathrm{iC}_{4}$ & 1.4721 & 0.4855 & 1.3797 & 1 & 0.2285 & 1.5959 & 1.4167 & 1.4005 & 2.1270 & 0.3423 & 0.9968 & 0.6577 & 0.6380 & 1.0896 & 2.1941 & 1.0669 \\
\hline$n \mathrm{C}_{4}$ & 1.2260 & 1.0441 & 0.9834 & 0.0391 & 1 & 0.7702 & 1.4128 & 1.2050 & 1.5494 & & 1.4731 & 0.5963 & & & 0.9721 & 1.2007 \\
\hline $\mathrm{iC}_{5}$ & 0.9716 & 0.9539 & -0.1373 & 1.3075 & 0.5426 & 1 & 1.2408 & 1.0552 & 1.9836 & 0.5592 & 0.6594 & 0.7738 & 0.7156 & & 2.0569 & 1.4441 \\
\hline$n \mathrm{C}_{5}$ & 0.7472 & 0.7392 & 0.8217 & 0.4225 & 0.7405 & 0.7790 & 1 & 0.9844 & 1.3209 & 0.4808 & 0.9647 & -0.0097 & 0.6563 & -0.1844 & 1.0379 & 0.5860 \\
\hline$n \mathrm{C}_{6}$ & 0.8776 & 0.2504 & 0.8534 & 0.7091 & 0.5629 & 0.6905 & 1.1873 & 1 & 1.4087 & 0.8976 & 1.0224 & 0.3292 & 0.7044 & 0.5056 & 1.6971 & 0.8131 \\
\hline$n \mathrm{C}_{7}$ & 1.0417 & 0.6311 & 0.6454 & 1.4746 & 0.5793 & 1.4968 & 0.7707 & 1.0708 & 1 & 0.7991 & 1.2859 & 1.4693 & 0.9132 & 0.6179 & 0.9665 & 0.4441 \\
\hline$n \mathrm{C}_{8}$ & 0.8523 & -0.0577 & -0.0396 & 0.5012 & 1.3937 & 0.6538 & 0.6957 & 0.9485 & 0.9518 & 1 & 1.1702 & 1.4315 & 0.8705 & 0.8448 & 35 & 0.5516 \\
\hline$n \mathrm{C}_{9}$ & 1.0746 & 0.8666 & 0.7225 & 1.0025 & 1.5967 & 0.6740 & 0.9116 & 0.9165 & 1.1707 & 1.1127 & 1 & 1.5099 & 0.8807 & 0.7958 & 0.8837 & 0.7751 \\
\hline$n \mathrm{C}_{10}$ & 0.9772 & -0.2604 & 0.9748 & 0.5833 & 0.5419 & 0.7729 & 0.1900 & 0.5074 & 1.4552 & 1.4278 & 1.5721 & 1 & 0.8600 & 0.1621 & 0.9988 & 0.3408 \\
\hline$n \mathrm{C}_{11}$ & 1.2777 & 0.7045 & 0.5444 & 0.6399 & 0.7085 & 0.7354 & 0.6987 & 0.7260 & 0.8833 & 0.8652 & 0.8853 & 0.8613 & 1 & 0.7109 & 0.7830 & 0.6836 \\
\hline $\mathrm{N}_{2}$ & 0.8780 & 0.7022 & 1.0776 & 2.2750 & 1.9103 & 2.6103 & 1.6150 & 2.2448 & 2.3715 & 0.8762 & 0.7854 & 0.3865 & 0.7240 & 1 & 0.5477 & 0.6180 \\
\hline $\mathrm{CO}_{2}$ & 1.7567 & 0.4470 & 1.0368 & 1.2846 & 0.4925 & 1.2710 & 0.6319 & 1.4300 & 1.4506 & 0.4590 & 0.8251 & 0.9205 & 0.7753 & 1.5818 & 1 & 0.9341 \\
\hline $\mathrm{H}_{2} \mathrm{~S}$ & 1.8908 & 1.2912 & 0.1105 & -0.1094 & 0.0408 & 0.4470 & -0.0498 & 0.6858 & 1.0477 & 0.5670 & 0.7695 & 0.4661 & 0.6967 & 0.6871 & 1.0975 & 1 \\
\hline
\end{tabular}

Table 3. Coefficients $\left(A_{i j}\right)$ for the calculation of the critical pressures.

\begin{tabular}{|c|c|c|c|c|c|c|c|c|c|c|c|c|c|c|c|c|}
\hline & $\mathrm{C}_{1}$ & $\mathrm{C}_{2}$ & $\mathrm{C}_{3}$ & $\mathrm{iC}_{4}$ & $n \mathrm{C}_{4}$ & $\mathrm{iC}_{5}$ & $n \mathrm{C}_{5}$ & $n \mathrm{C}_{6}$ & $n \mathrm{C}_{7}$ & $n \mathrm{C}_{8}$ & $n \mathrm{C}_{9}$ & $n \mathrm{C}_{10}$ & $n \mathrm{C}_{11}$ & $\mathrm{~N}_{2}$ & $\mathrm{CO}_{2}$ & $\mathrm{H}_{2} \mathrm{~S}$ \\
\hline $\mathrm{C}_{1}$ & 1 & 0.4493 & 1.7187 & 0.8000 & 1.1772 & 1.8921 & 2.1290 & 1.1844 & 1.4133 & 1.6876 & 0.8561 & 1.1680 & 0.6715 & 0.4848 & 0.4799 & 0.8429 \\
\hline $\mathrm{C}_{2}$ & 1.6543 & 1 & 1.8534 & 2.2280 & 1.5786 & 2.2176 & 1.6643 & 1.9969 & 1.8780 & 0.5850 & 0.8439 & 0.6767 & 1.0277 & 0.0273 & 1.3482 & 0.5759 \\
\hline $\mathrm{C}_{3}$ & 0.4168 & 0.4199 & 1 & 1.2763 & 1.1020 & 0.7668 & 1.2150 & 1.6577 & 2.0286 & -0.1428 & 0.5810 & 0.4093 & 0.8462 & 0.1773 & 0.4761 & 1.9350 \\
\hline $\mathrm{iC}_{4}$ & 0.7662 & 0.5124 & 1.2328 & 1 & 0.6932 & 1.7257 & 0.9364 & 1.4341 & 2.2122 & 1.0330 & 0.9785 & 0.7599 & 1.0073 & 0.1109 & 0.7723 & 1.3543 \\
\hline$n \mathrm{C}_{4}$ & 0.6923 & 0.5345 & 0.8656 & 0.4870 & 1 & 2.4311 & 1.0916 & 1.2199 & 1.4788 & 0.7470 & 0.8565 & 0.8695 & 0.7881 & 0.3425 & 0.3072 & 1.1769 \\
\hline $\mathrm{iC}_{5}$ & 0.3707 & -0.1767 & 0.2611 & 1.6818 & 2.4561 & 1 & 1.2725 & 0.8114 & 1.1113 & 0.6663 & 0.6085 & 0.6469 & 0.7920 & 0.4801 & 1.2830 & 1.4351 \\
\hline$n \mathrm{C}_{5}$ & 0.1613 & 0.4628 & 0.7668 & 0.4020 & 0.9669 & 0.6032 & 1 & 1.6196 & 1.2591 & & 0.7487 & 0.8992 & 0.7071 & 0.4044 & 1.0361 & 1.0719 \\
\hline$n \mathrm{C}_{6}$ & 0.3377 & 0.1743 & 0.6624 & 0.8900 & 0.3007 & 0.2835 & 1.6281 & 1 & 0.8953 & 0.8306 & 0.8254 & 0.9909 & 0.7949 & 0.2013 & 0.9734 & 0.5825 \\
\hline$n \mathrm{C}_{7}$ & 0.2890 & 0.3458 & 0.4363 & 1.6808 & 0.6179 & 0.3753 & 0.8607 & 0.4851 & 1 & 1.1314 & 1.2686 & 1.3125 & 1.0520 & 0.5291 & -0.1096 & 0.2238 \\
\hline$n \mathrm{C}_{8}$ & 0.9964 & 0.7479 & 0.5508 & 1.0473 & 1.0303 & 0.7390 & 0.7238 & 0.8570 & 1.1182 & 1 & 1.1123 & 1.2436 & 0.9409 & 0.7953 & 0.5601 & 0.7651 \\
\hline$n \mathrm{C}_{9}$ & 0.7201 & 0.8508 & 0.7431 & 1.0007 & 1.0223 & 0.6767 & 0.8092 & 0.8282 & 1.1434 & 1.1214 & 1 & 1.2499 & 0.9269 & 0.7413 & 0.8359 & 0.7979 \\
\hline$n \mathrm{C}_{10}$ & 0.9754 & 0.6623 & 0.5661 & 0.7703 & 0.9964 & 0.6638 & 1.0018 & 1.0261 & 1.2367 & 1.2441 & 1.2433 & 1 & 0.9131 & 0.5848 & 0.6993 & 0.6204 \\
\hline$n \mathrm{C}_{11}$ & 0.7364 & 1.1445 & 0.9435 & 1.0027 & 0.7928 & 0.7842 & 0.7479 & 0.7812 & 0.9575 & 0.9448 & 0.9270 & 0.9148 & 1 & 0.7365 & 0.7209 & 0.7657 \\
\hline $\mathrm{N}_{2}$ & 1.6568 & 1.8121 & 2.1740 & 2.4239 & 2.5180 & 2.5666 & 2.4935 & 2.4670 & 2.4706 & 0.7987 & 0.7466 & 0.6831 & 0.7436 & 1 & 2.4106 & 4.6775 \\
\hline $\mathrm{CO}_{2}$ & 1.6649 & 0.6463 & 0.9745 & 1.4818 & 1.5878 & 2.1701 & 1.8296 & 2.1203 & 2.0246 & 0.5833 & 0.8012 & 0.7050 & 0.7262 & -0.0435 & 1 & 1.4059 \\
\hline $\mathrm{H}_{2} \mathrm{~S}$ & 1.0680 & 1.1258 & 0.3952 & 0.0853 & 0.2068 & 0.5952 & 0.7155 & 1.5382 & 1.6385 & 0.7569 & 0.7904 & 0.5976 & 0.7629 & -1.2622 & 0.6698 & 1 \\
\hline
\end{tabular}


(a)

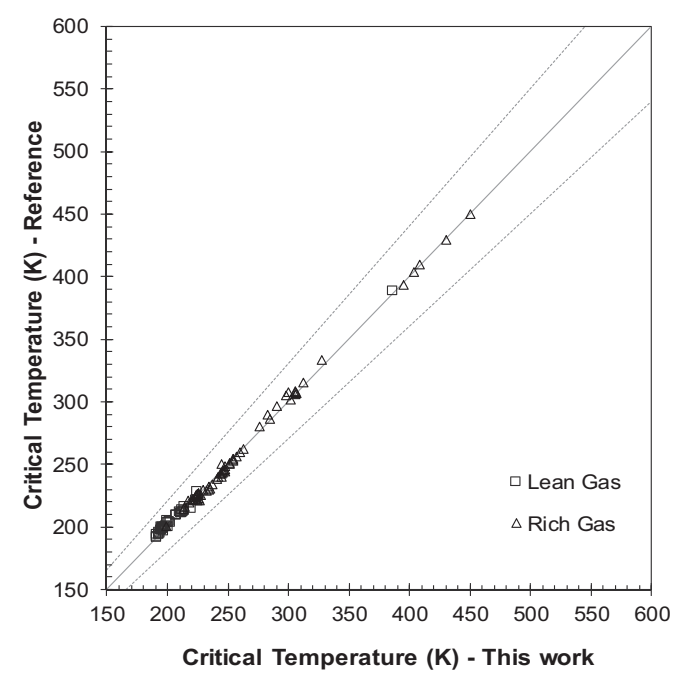

(b)

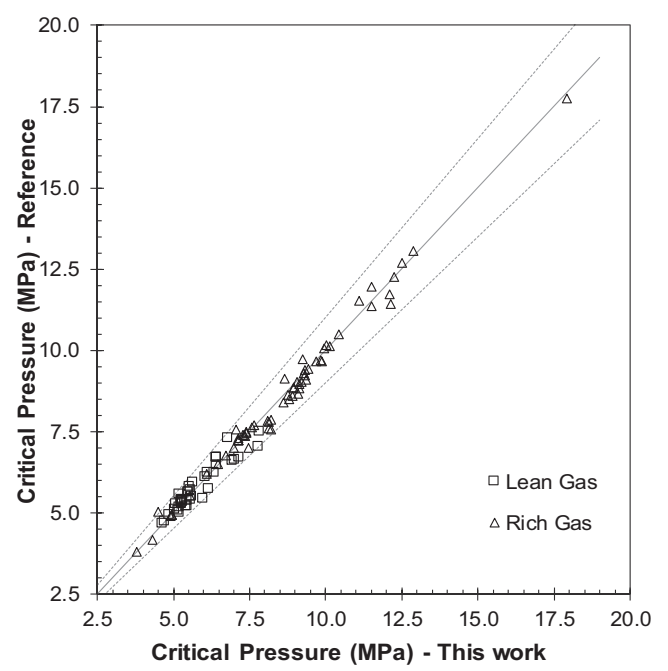

(c)

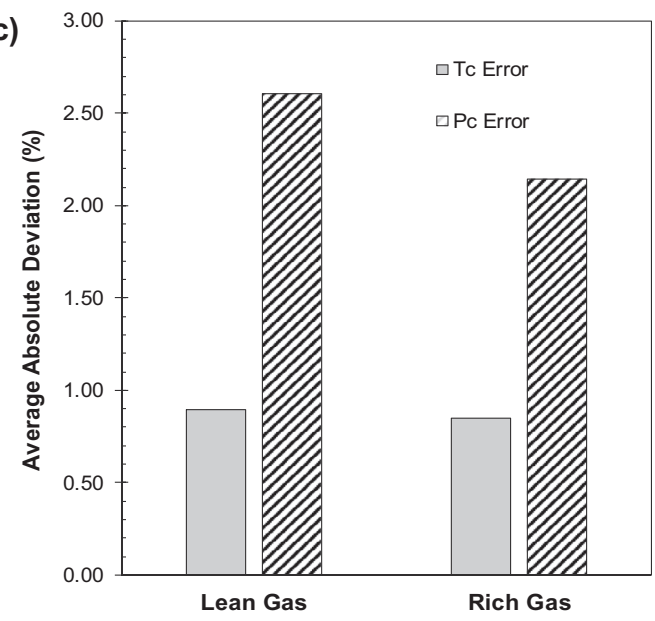

Fig. 4. Critical property calculations - Comparison A: a) critical temperatures, b) critical pressures, and c) Average Absolute Deviation (AAD).

Table 4. Critical property calculations - Comparison B.

\begin{tabular}{|c|c|c|c|c|c|c|}
\hline \multirow[t]{3}{*}{$n \mathrm{C}_{7}$ content } & \multicolumn{4}{|c|}{ Percentage error comparison } & \multirow{2}{*}{\multicolumn{2}{|c|}{$\begin{array}{l}\text { Improvement } \\
\text { (this work) }\end{array}$}} \\
\hline & \multicolumn{2}{|c|}{ Peng (1986) } & \multicolumn{2}{|c|}{ This work } & & \\
\hline & $T_{\mathrm{c}}(\%)$ & $P_{\mathrm{c}}(\%)$ & $T_{\mathrm{c}}(\%)$ & $P_{\mathrm{c}}(\%)$ & $T_{\mathrm{c}}(\%)$ & $P_{\mathrm{c}}(\%)$ \\
\hline Until $n \mathrm{C}_{7}\left(\leq n \mathrm{C}_{7}\right)$ & 0.674 & 3.991 & 0.517 & 1.985 & 23.26 & 50.26 \\
\hline$n \mathrm{C}_{7}$ plus $\left(>n \mathrm{C}_{7}\right)$ & 1.451 & 8.494 & 1.024 & 2.540 & 29.42 & 70.10 \\
\hline General & 1.213 & 7.118 & 0.869 & 2.370 & 28.38 & 66.70 \\
\hline
\end{tabular}

equal or lighter than $n \mathrm{C}_{11}$ were considered as one component, and grouped as the heavy fraction of the mixture, assuming this fraction as $n \mathrm{C}_{7}$ plus $\left(n \mathrm{C}_{7}^{+}\right)$(Huang and Guo, 1995).

The improvement made to the semi-empirical model of Peng (1986), for the calculation critical properties in natural gas mixtures is noticed by reducing significantly a significant reduction of the average errors of $28.38 \%$ for the critical temperature and $66.70 \%$ for the critical pressure, applicable to natural gas mixtures with significant amounts of both light and heavy compounds. 
Table 5. Critical property calculations - Comparison C.

\begin{tabular}{|c|c|c|c|c|c|}
\hline \multirow[t]{3}{*}{ Model } & \multicolumn{4}{|c|}{ Percentage error comparisons } & \multirow[t]{3}{*}{ References } \\
\hline & \multicolumn{2}{|c|}{ Using simulators } & \multicolumn{2}{|c|}{ Experimental data } & \\
\hline & $T_{\mathrm{c}}(\%)$ & $P_{\mathrm{c}}(\%)$ & $T_{\mathrm{c}}(\%)$ & $P_{\mathrm{c}}(\%)$ & \\
\hline $\mathrm{A}$ & 0.644 & 0.898 & 1.731 & 3.141 & Justo-García et al. (2008) \\
\hline B & 0.237 & 0.532 & 1.289 & 2.639 & \\
\hline This work & 0.332 & 2.511 & 1.015 & 3.321 & \\
\hline $\mathrm{C}$ & 0.142 & 0.287 & - & - & Nasrifar et al. (2005) \\
\hline This work & 0.438 & 2.542 & - & - & \\
\hline $\mathrm{D}$ & 2.160 & 1.305 & 0.900 & 8.076 & Guerrero-Zárate et al. (2017) \\
\hline This work & 1.063 & 2.874 & 0.830 & 3.112 & \\
\hline $\mathrm{E}$ & 0.756 & 2.926 & 0.572 & 2.283 & Jiang and Prausnitz (2000) \\
\hline This work & 0.441 & 1.560 & 0.982 & 1.663 & \\
\hline
\end{tabular}

Note: Letters A, B, C, D and E are used to identify the models shown in the referenced articles.

\subsubsection{Comparison $C$}

Comparison C (Tab. 5) considers other suggested models to calculate critical properties: (i) using simulators with the Peng-Robinson EoS and (ii) using experimental data reported by different authors (Jiang and Prausnitz, 2000; Justo-García et al., 2008; Nasrifar et al., 2005; GuerreroZárate et al., 2017).

In general terms, average errors obtained using the adjustment of the coefficient matrix $A_{i j}$ performed in this study are comparable to those average errors obtained by other authors, using as reference the values from the simulators and experimental data. This proves the power of coefficient matrices $A_{i j}$ developed in this study to calculate critical properties of natural gas mixtures, which is applicable to natural gas mixtures containing significant amounts of heavy hydrocarbons components, (up to $n \mathrm{C}_{11}$ ).

\section{Conclusion}

This study proposes a modification to the semi-empirical model advanced by Peng (1986) for the calculation of the critical properties in natural gas mixtures, aiming to extend its application to rich natural gas streams, i.e., natural gas mixtures containing significant amounts of heavy hydrocarbons (up to $n \mathrm{C}_{11}$ ). The proposed modification focuses on establishing new matrices of coefficients $A_{i j}$ used in the calculation. Different comparisons were made between the experimental and reference values of the critical properties, which show the robustness of the improvement of the semi-empirical model as an easy-touse engineering tool for estimating the critical properties in natural gas mixtures, applicable to both lean and rich gas mixtures. The average errors obtained are less than $1.00 \%$ and $2.70 \%$ for calculating the critical temperature and pressure, respectively.
Acknowledgments. The authors would like to owe great thanks to Arlán Briceño and Jean-Piero Suárez, at Universidad Central de Venezuela for their technical advices.

\section{References}

Ahmed T. (2016) Equations of state and PVT analysis: Applications for improved reservoir modeling, 2nd edn., Gulf Professional Publishing - Elsevier Inc., Cambridge, USA.

Atilhan M., Ejaz S., Zhou J., Cristancho D., Mantilla I., Holste J., Hall K. (2010) Characterization of deepwater natural gas samples. Part 1: $78 \%$ methane mixture with heavy components, J. Chem. Eng. Data 55, 4907-4911.

Ávila S., Blanco S., Velasco I., Rauzy E., Otín S. (2002) Thermodynamic properties of synthetic natural gases. 1 . Dewpoint curves of synthetic natural gases and their mixtures with water and methanol. Measurement and correlation, Ind. Eng. Chem. Res. 41, 3714-3721.

Ávila S., Benito A., Berro C., Blanco S., Otín S., Velasco I. (2006) Dew-point curves of natural gas. Measurement and modeling, Ind. Eng. Chem. Res. 45, 5179-5184.

Bahadori A. (2014) Natural gas processing: Technology and engineering design, Gulf Professional Publishing - Elsevier Inc., Waltham, USA.

Bell I., Jäger A. (2017) Calculation of critical points from Helmholtz-energy-explicit mixture models, Fluid Phase Equilib. 433, 159-173.

Campos A., da Silva N., Pereira M., Vasconcelos M. (2017) A review of Brazilian natural gas industry: Challenges and strategies, Renew. Sust. Energ. Rev. 75, 1207-1216.

Demirel N., Demirel T., Deveci M., Vardar G. (2017) Location selection for underground natural gas storage using Choquet integral, J. Nat. Gas Sci. Eng. 45, 368-379.

Faramawy S., Zaki T., Sakr A. (2016) Natural gas origin, composition, and processing: A review, J. Nat. Gas Sci. Eng. 34, 34-54.

Farzaneh-Gord M., Niazmand A., Deymi-Dashtebayaz M., Rahbari H. (2015) Effects of natural gas compositions on 
CNG (compressed natural gas) reciprocating compressors performance, Energy 90, 1, 1152-1162.

Foo D., Chemmangattuvalappil N., Ng D., Elyas R., Chen C., Elms R., Lee H., Chien I., Chong S., Chong C. (2017) Chemical engineering process simulation, 1st edn., Elsevier, Amsterdam, Netherlands.

Gas Processors Suppliers Association (1998) Engineering data book, 11th edn., GPSA, Tulsa, Okla.

Guerrero-Zárate D., Estrada-Baltazar A., Iglesias-Silva A. (2017) Calculation of critical points for natural gas mixtures with the GERG-2008 equation of state, Fluid Phase Equilib. 437, 69-82.

Heidemann R., Khalil M. (1980) The calculation of critical points, AlChE J. 26, 2, 769-779.

Huang Q., Guo T. (1995) Prediction of the critical points of natural gas mixtures by rigorous and semi-empirical methods, J. Pet. Sci. Eng. 13, 3-4, 233-245.

International Organization for Standardization (2000) Natural gas - Determination of composition with defined uncertainty by gas chromatography - Part 4: Determination of nitrogen, carbon dioxide and $C_{1}$ to $C_{5}$ and $C_{6}+$ hydrocarbons for $a$ laboratory and on-line measuring system using two columns (ISO 6974-4:2000).

Jaeschke M., Humpherys A. (1991) The GERG databank of high accuracy compressibility factor measurements, Fortschr.-Ber. VDI Reihe 6, 251, 58.

Jiang J., Prausnitz J. (2000) Critical temperatures and pressures for hydrocarbon mixtures from an equation of state with renormalization-group theory corrections, Fluid Phase Equilib. 169, 127-147.

Jin C., Lim Y. (2018) Economic evaluation of NGL recovery process schemes for lean feed compositions, Chem. Eng. Res. Des. 129, 297-305.

Justo-García D., García-Sánchez F., Águila-Hernández J., Eustaquio-Rincón R. (2008) Application of the simulated annealing technique to the calculation of critical points of multicomponent mixtures with cubic equations of state, Fluid Phase Equilib. 264, 164-173.

Kunz O., Wagner W. (2012) The GERG-2008 wide-range equation of state for natural gases and other mixtures: An expansion of GERG-2004, J. Chem. Eng. Data 57, 3032-3091.

Louli V., Pappa G., Boukouvalas C., Skouras S., Solbraa E., Christensen K., Voutsas E. (2012) Measurement and prediction of dew point curves of natural gas mixtures, Fluid Phase Equilib. 334, 2012, 1-9.

Marquardt D. (1963) An algorithm for least-squares estimation of nonlinear parameters, J. Soc. Ind. Appl. Math. 11, 2, 431-441.

MathWorks (2018) Optimization toolbox ${ }^{\text {TM }}$ user's guide. Version 8.2 (R2018b), The MathWorks Inc, Natick, USA.

Mazyan W., Ahmadi A., Ahmed H., Hoorfar M. (2016) Market and technology assessment of natural gas processing: A review, J. Nat. Gas Sci. Eng. 30, 487-514.

Michelsen M. (1980) Calculation of phase envelopes and critical points for multicomponent mixtures, Fluid Phase Equilib. 4, $1-2,1-10$.

Nasir Q., Sabil K., Lau K. (2015) Measurement of isothermal (vapor + liquid) equilibria, (VLE) for binary $\left(\mathrm{CH}_{4}+\mathrm{CO}_{2}\right)$ from $\mathrm{T}=(240.35$ to 293.15$) \mathrm{K}$ and $\mathrm{CO}_{2}$ rich synthetic natural gas systems from $\mathrm{T}=(248.15$ to 279.15$) \mathrm{K}$, J. Nat. Gas Sci. Eng. 27, 1, 158-167.

Nasrifar K., Bolland O., Moshfeghian M. (2005) Predicting natural gas dew points from 15 equations of state, Energy Fuels 19, 561-572.

Nasrifar K., Rahmanian N. (2018) Equations of state with group contribution binary interaction parameters for calculation of two-phase envelopes for synthetic and real natural gas mixtures with heavy fractions, Oil Gas Sci. Technol. - Rev. IFP Energies nouvelles 73, 7.

Peng D. (1986) An empirical method for calculating vaporliquid critical points of multicomponent mixtures, Can. J. Chem. Eng. 64, 827-830.

Peng D., Robinson D. (1976) A new two-constant equation of state, Ind. Eng. Chem. Fundam. 15, 1, 59-64.

Peng D., Robinson D. (1977) A rigorous method for predicting the critical properties of multicomponent systems from an equation of state, AlChE J. 23, 2, 137-144.

Sayed M., Al-Muntasheri G. (2016) Mitigation of the effects of condensate banking: A critical review, SPE Prod. Oper. 31, 2, 85-102.

Sloan E., Koh C. (2008) Clathrate hydrates of natural gases, 3rd edn., CRC Press, Taylor \& Francis, New York, NY.

Yang Y., Li J., Wang S., Wen C. (2018) Gas-liquid two-phase flow behavior in terrain-inclined pipelines for gathering transport system of wet natural gas, Int. J. Press. Vessels Piping 162, $52-58$. 